\section{Influence of deprivation on the frustration effect*}

\author{
WILLIAM P. DUNLAP $\dagger$ and SARAH B. FRATES \\ Tulane University, New Orleans, La. 70118
}

Groups of male albino rats under 0-h food deprivation were compared to groups under 22-h food deprivation running to sucrose-pellet reward in the double alley. In addition to experimental groups switched from continuous to $50 \%$ reinforcement in the first goalbox (GB1), control groups never receiving reward in GB1 were used under both deprivation conditions. A substantial frustration effect (FE) was found for the 22-h-deprived groups; however, no reliable evidence of the FE was found with 0 -h-deprived groups.

A direct relation between drive level and magnitude of the frustration effect $(F E)$ is implicit in the theoretical statements of Amsel (1958) and Spence (1960). The rather meager experimental data concerning this issue tends to confirm this relationship. Marzocco (1951) found that the increase in barpress strength following nonreward was a direct function of hours of food deprivation. McHose \& Ludvigson (1964), using the double-alley runway, found a reduced and statistically nonsignificant FE with Ss at $90 \%$ body weight as compared to a significant $\mathrm{FE}$ for Ss at $80 \%$ body weight; however, their study lacked an important control. Wagner (1959) has pointed out that the FE in the double-alley situation cannot legitimately be attributed to frustration unless the response strength following nonreward in the first goalbox is not only greater than that following reward, but also greater than the performance of a control group that is never rewarded $(0 \%)$ in the first goalbox.

The present study compared the FE under $22 \mathrm{~h}$ of food deprivation to the FE under $0 \mathrm{~h}$ of food deprivation and employed the appropriate $0 \%$ control groups. A highly palatable sucrose pellet reward was used to maintain running behavior under these deprivation conditions. The 0 -h food-deprivation groups are of special interest, since Dachowski \& Dunlap (1969) and Dunlap (1969) have shown that two other partial-reinforcement phenomena, the partial-reinforcement effect (PRE) and the

\footnotetext{
*This paper is based on a portion of a thesis submitted by $S$. B. Frates in partial fulfillment of the requirements for the Master's degree: Lawrence Dachowski was the faculty research supervisor. The study was supported by PHS Research Grant No. MH12099 from the National Institute of Mental Health. Computer processing of the data was supportcd by the Computer Laboratory of Tulane University. The authors wish to thank Holland Jones and Larry Hughes for assistance in gathering and transcribing the data. A version of this paper was presented at the convention of the Southwestern Psychological Association. St. Louis, Mo.. 1970.

$\nmid$ Requests for reprints should be sent to William P. Dunlap, Department of Psychology, Tulane University, New Orleans, La. 70118.
}

crossover effect (CE), were present under this zero-deprivation condition.

\section{SUBJECTS}

Data were obtained from 24 experimentally naive male albino rats from Rolfsmeyer Co., Madison, Wisconsin. Ss were 94 days old at the beginning of the experiment and were housed in individual cages under a reversed 24 ht light-dark cycle.

\section{APPARATUS}

The double runway used (described in Dachowski, 1967) was 3 in. wide, $3^{1 / 2}$ in. high, and divided by opaque guillotine doors into a 10-in. startbox (SB), a 16-in. runway (R1), a 14-in. goalbox (G1), a $39-3 / 8$-in. second runway (R2), and a 14-in. second goalbox (G2). The first three sections of the runway were painted black and had a wooden floor; R2 and G2 were painted white and had a hardware cloth floor. Clear plastic guillotine doors were mounted behind the opaque doors between $\mathrm{SB}$ and $\mathrm{R} 1$ and between $\mathrm{G} 1$ and $\mathrm{R} 2$. Photocells located 2 in., 14 in., and 46 in. from G1 measured start, running, and goal entry times in the second alley. The $3 \frac{12}{2} \times 11$ in. pretraining box was painted gray.

\section{PROCEDURE}

The basic design was a 2 by 2 factorial with two levels of food deprivation ( 0 and $22 \mathrm{~h}$ ) and two schedules of $\mathrm{G} 1$ reward (50\% and 0\%). A 7-day pretraining procedure was used to accustom the Ss to eating the reward pellets $(37-\mathrm{mg}$ sucrose from P.J. Noyes Co.) under no food deprivation. ' From Days 1 to 4 a decreasing number of sucrose pellets $(40$, 20,10 , and then 5) were given in the home cage. From Days 2 to 7 an increasing amount of practice eating pellets in the pretraining box $(\mathrm{PB})$ was given. On Day 2 and Day 3 one trial was given with five pellets in PB; on Day 4 two trials with three pellets, and on Days 5,6, and 7, four trials with three pellets present were given. On the last 3 days a 15-sec time limit in PB was enforced and latency to start of eating was recorded. The Ss were ranked on a basis of eating latency, and three Ss were dropped for failure to eat pellets. Twenty-four Ss were assigned to matched groups on a basis of the rankings. Over the next 5 days, Ss in the 22-h groups were adapted to the deprivation schedule; then 5

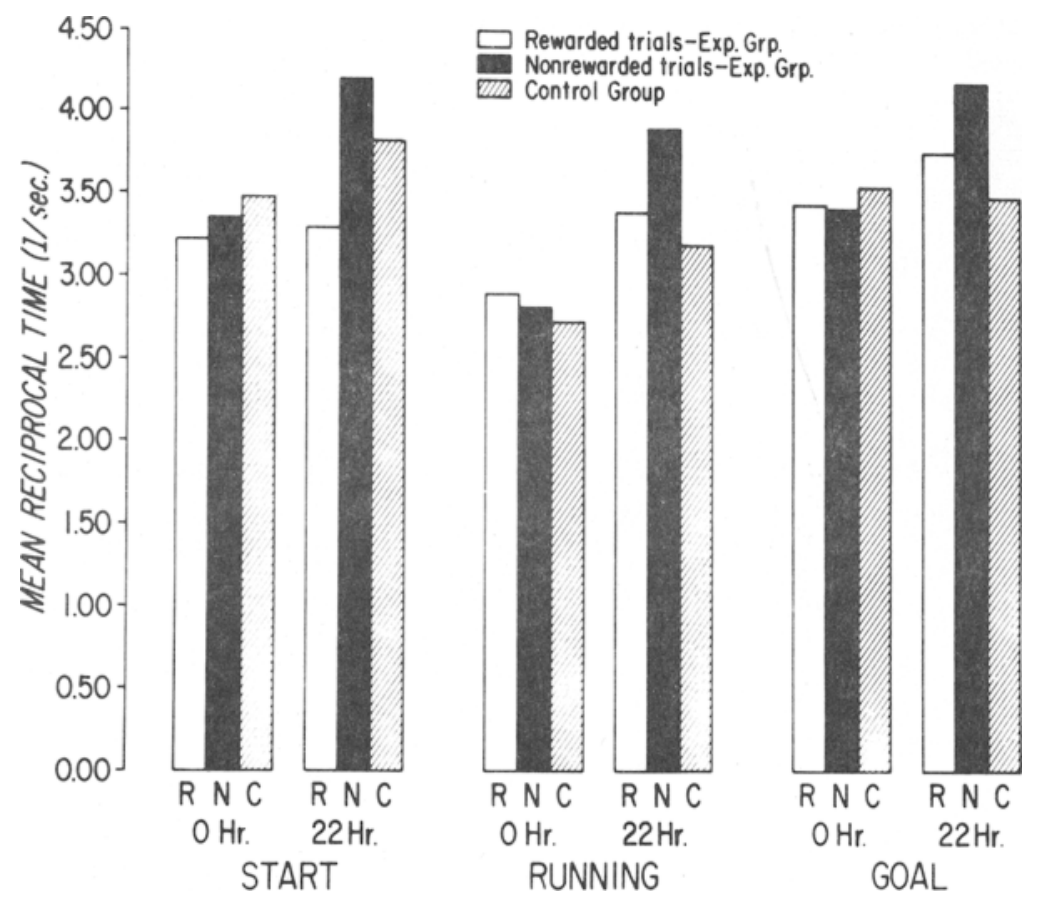

Fig. 1. Mean postshift start, running, and goal-entry speeds for the 0 -h and 22 -h deprivation groups. [The $0 \%$-control group means (C) represent 20 trials. Rewarded (R) and nonrewarded $(\mathrm{N})$ 50\% group means represent 10 trials.] 
more days of pellet-eating practice were given to all $\mathrm{Ss}$ in $\mathrm{PB}$.

On each of the first 2 days of runway training, one trial was given. On the third day two trials were given, and thereafter acquisition proceeded at a rate of four trials per day. A trial consisted of placing $S$ in SB facing away from R1. The opaque door was raised, and after $S$ had oriented toward R1 for $1 \mathrm{sec}$, the transparent door was raised. All Ss were detained in G1 and G2 for $15 \mathrm{sec}$, whether reward was present or not. Ss were run in squads of eight, composed of two Ss from each group. All $S s$ in a squad completed a given trial before the next trial was run. This procedure maintained an intertrial interval of approximately $10 \mathrm{~min}$. The $50 \%$ Ss received a four-pellet reward in $G 1$ on every trial for the first 48 trials. On Trial 49 these Ss were switched to a $50 \%$ reward schedule in $\mathrm{G} 1$ that consisted of random permutations of the following four sequences of rewarded (R) and nonrewarded (N) trials: RNRN, RNNR, NRRN, and NRNR. Twenty postshift 50\% trials were run. With these sequences two FEs could be evaluated during the first and second two-trial periods of each day. The $0 \%$ Ss were never rewarded in G1. All Ss were consistently rewarded with two pellets in G2.

\section{RESULTS}

The postshift R2 latencies were transformed to reciprocals (running and goal-entry speeds are expressed in $\mathrm{ft} / \mathrm{sec}$ ); second alley start, running, and goal-entry speeds were separately analyzed. As can be seen in Fig. 1, a substantial FE was found for 22-h-deprived Ss. The significance of the overall $\mathrm{FE}$ for the $50 \%$ groups in start $(\mathrm{F}=7.616, \mathrm{df}=1 / 10, \mathrm{p}<.05)$, running $(F=11.071, \quad$ df $=1 / 10, \quad p<.01), \quad$ and goal-entry speed $(F=6.067, \mathrm{df}=1 / 10$, $p<.05)$ verifies this observation. Also, in running and goal-entry speed the $22-\mathrm{h} / 50 \%$ group performance is clearly above the $22-\mathrm{h} / 0 \%$ control group performance; thus, the $\mathrm{FE}$ is legitimate. With zero-deprived Ss, however, on no speed measure did performance following nonreward surpass both speed following reward and the appropriate $0 \%$ control speed. Thus, under the zero-deprivation condition, there was no evidence of a legitimate FE. This finding was reflected in a significant FE by Deprivation interaction for running $(\mathrm{F}=18.593, \mathrm{df}=1 / 10, \mathrm{p}<.01)$ and goal entry $(F=7.967, \quad d f=1 / 10, \quad p<.05)$ speeds. No interaction involving the days variable was significant for any speed measure.

The only possible evidence of a tendency for the development of the FE in the zero-deprived group was a curious Deprivation by $\mathrm{FE}$ by Periods interaction in goal-entry speed $(\mathrm{F}=10.046, \mathrm{df}=1 / 10$, $\mathrm{p}<.01)$. On this one speed measure, the zero-deprived Ss showed slower speeds following nonreward than following reward during the first period (Trials 1 and 2 of each day); however, during the second period (Trials 3 and 4 each day), they showed superior performance following nonreward. When this apparent FE during the second period was compared to the appropriate $0 \% / z e r o-d e p r i v e d$ control performance, however, the apparent $\mathrm{FE}$ was invalidated, the $0 \%$ group performance being nearly equal to that of the $50 \%$ group performance following nonreward. As shown in Fig. 1, the various runway speeds for zero-deprived groups were in general only slightly slower than the comparable speeds of the 22-h-deprived groups; thus, the absence of the FE under the zero-deprivation condition cannot be explained as due simply to minimal runway performance on the part of these Ss.

\section{DISCUSSION}

The absence of the FE under the zero-deprivation condition confirms the predicted relation between hours of deprivation and the frustration effect. The comparison of 22-h and $0-\mathrm{h}$ deprived $50 \%$ groups to the appropriate $0 \%$ controls considerably strengthens the argument for this relation. Using Amsel's (1958) terms, one may conclude that magnitude of primary frustration produced by nonreward is clearly a function of drive.

The absence of the FE under the zero-deprivation condition is of additional interest in light of the finding of a significant CE and PRE by Dachowski \& Dunlap (1969) and Dunlap (1969), using the same zero-deprivation treatment with sucrose pellet reward. These findings suggest that although the $\mathrm{FE}$ is drive dependent, the other two partial reinforcement phenomena, the $C E$ and PRE, are relatively insensitive to drive level. These data lend support to an explanation of the PRE and CE based on learning processes rather than on drive processes.

The procedure of running $\mathrm{Ss}$ under zero-deprivation to highly palatable reward appears to be a very promising method of partialing out directly drive-related effects from other behavior in instrumental learning situations. Compared to the performance of Ss under food deprivation, nondeprived $S$ s showed both stable and high levels of running behavior in the present study; and, with the pretraining procedure described, no $S$ had to be dropped during runway training for failure to perform.

\section{REFERENCES}

AMSEL, A. The role of frustrative nonreward in noncontinuous reward situations. Psychological Bulletin, 1958, 55, 102-119.

DACHOWSKI, L. Reward size effects in the double runway. Psychonomic Science, 1967, 9, 157-158.

DACHOWSKI, L., \& DUNLAP, W. P. Frustrative nonreward effects in acquisition under zero hours deprivation. Psychonomic Science, 1969, 14, 113-114.

DUNLAP, W. P. Partial reinforcement phenomena with highly palatable rewards in the absence of food deprivation. Unpublished doctoral dissertation, Tulane University, 1969.

FRATES, S. B. Influence of deprivation on the frustration effect. Unpublished Master's thesis, Tulane University, 1970.

MARZOCCO, F. N. Frustration effect as a function of drive level, habit strength and distribution of trials during extinction. Unpublished doctoral dissertation, State University of Iowa, 1951.

McHOSE, J. H., \& LUDVIGSON, H. W. Frustration effect as a function of drive. Psychological Reports, 1964, 14, 371-374.

SPENCE, K. W. Behavior theory and learning. Englewood Cliffs, N.J: Prentice Hall, 1960.

WAGNER, A. R. The role of reinforcement and nonreinforcement in an "apparent frustration effect." Joumal of Experimental Psychology, $1959,57,130-136$.

NOTE

1. For further detail on the pretraining and $S$ selection procedure, see Frates (1970). 